\title{
Proposition of the Project Management Framework through Integration of the Knowledge and Information of the Collaborative Decision Making Processes
}

\author{
Marija Jankovic, Julie Le Cardinal, Jean-Claude Bocquet \\ Industrial Engineering Department, Ecole Centrale Paris, Grande Voie des Vignes, 92295 Chatenay- \\ Malabry, France \\ E-mail : marija.jankovic@ecp.fr
}

Abstract: The first phase in new product development process is a specific phase. It is a phase of project definition. It is also a collaborative decision making phase. In this phase the project objectives are to be defined and thus it is very difficult to manage this phase with classic project management tools.

In this paper we propose a new project management tool structure. This tool was developed upon the collaborative decision making information capitalisation in order to structure and organise this phase. The necessary information in this tool is identified by a model developed using the systemic approach.

Keywords: Collaborative decision making, New Product Development, Project Management, Decision making information

Reference to this paper should be made as follows: Name, X. (XXXX), "Paper Title", International Journal of Product Development, Special Issue "Content Management in Concurrent Product Development Structures", Vol. X, No. Y, pp 00-00.

Bibliographical notes: Marija Jankovic finished her studies in Belgrade on the Faculty of Organisational Sciences. In 2001, she obtained a scholarship from the French Government for Master of Industrial Engineering in Ecole Centrale Paris. She started her PhD thesis in 2002 in Industrial Engineering Laboratory (Ecole Centrale Paris). Her research work was done in collaboration with PSA Peugeot Citroen. Parallel she occupies the place of assistant and teaches in Ecole Centrale Paris.

\section{Introduction}

The first phase of New Product and Process Development (NPPD) is a phase where different project members collaboratively decide the project objectives. This first phase of New Product and Process Development is specific because it is a collaborative decision making phase. Different actors in this process make strategic decision concerning the project in this phase. Whelton (Whelton, Ballard et al. 2002) indicates that in the early phases almost $80 \%$ of the product and industrial process are specified. Bellut (Bellut 1990) in his work exposes that any decision in the engineering phase will have nine times greater financial consequence than the ones made in the manufacturing phase. Therefore, we can underline the importance if this phase for the project success.

As this phase is a phase of project definition, the classic project management tools are not sufficient. Further in this paper we expose the context of this phase and the reasons of insufficiency of existing project management tools. Here we propose a conceptual project management framework for this 
early phase based upon the capitalisation of information in the collaborative decision-making. Therefore, this phase is managed by decisions and using collaborative decision making information identified as necessary for the definition of the project objectives.

The structure of this paper is organised in four parts. The first part is related to the project management issues in the early stage of product and process development. In this paper we expose some concrete aspects of this phase identified during our field research. Based upon the conclusions of our research field we propose a management framework for the project management tool that we developed in order to cover some of the issues that were identified. In this second part we develop the structure of this framework and its implementation. In the third part, we discuss the collaborative decision-making model used as a basis for the development of the proposed framework. In the end we discuss some of our conclusions and possible perspectives for the future research.

\section{Management of the Product Development Process in its Early Phase} New Product and Process Development (NPPD) is one of the crucial areas of company competences and is contributing positively to the company success (Harmsen, Grunert et al. 2000). The beginning of this process is the definition of the clients needs resulting from the market research phase. The Project Definition phase, as it is called, is the first phase of the NPPD process in PSA Peugeot Citroen., for instance.

The Project Definition phase is also very complex because:

- It is a phase where all aspects of one project are to be defined,

- Project organisation and management are set up throughout the fulfilment of functions, assigned to every project team member,

- It is a phase of convergence of project objectives through the collaborative decision-making process,

- Management bases, as well as the motivation of project team, are built up progressively throughout this phase.

The Project Definition phase is a NPPD phase where the project objectives are defined. At the very beginning of this phase, the project team disposes with information related to the client needs, expressed as qualitative description of what is accepted. This information is a result of a thorough market research study. The content of this information can be: the client of this segment wants a spacious car, comfortable, with elegant lines and incorporating the innovations relating to the comfortable driving sensations. This information is a starting point for the project team to define the precise vehicle characteristics: length $4,2 \mathrm{~m}$, height $1,5 \mathrm{~m}$, masse $2 \mathrm{t}$, etc. The mission of the project team is not only to define the development objectives for the product, i.e. vehicle, but also for the project in terms of costs, quality, risks. Moreover, it is necessary to verify that the defined vehicle objectives are coherent: Does the introduction of one innovation increases the vehicle mass? If the 
mass is increased; is it sufficient to introduce the motorisation of 138 horses? If the motor is changed, is it possible that the driving sensations are perceived as comfortable? The complexity of vehicle development lies precisely in high interdependence of development fields.

In order to develop an adequate support for project scheduling it is necessary to have defined project objectives. The project management methodology proposes the development of different approaches (project planning, quality management, cost optimisation, etc.) based upon clearly defined project objectives. Therefore, we can notice the difficulty to manage this early phase when the needs are contradictory to this proposed logics

Moreover, the fact that in this early phase the project team has a difficulty to define the project schedule introduces the problem of the project control. How it is possible to control something when there is no possibility to compare the executed with the planified? Indeed, the existing control of this phase in PSA Peugeot Citroen is at the very end of this phase when all the project objectives are defined. The control is carried out by the upper management level, i.e. the Senior Directors level. At this stage the senior level gives a "go" or a "no go" decision. If the decision is "no go" the delay of the project can be increased up to several months.

The Project Definition phase is also a decision-making phase, more precisely the collaborative decision-making phase. Collaborative decisions are made by different actors participating in the definition process of project objectives that have different and often opposite objectives. In the project every actor is responsible for one part or aspect of the vehicle development, and thus has the vision and knowledge "coloured" by the information of its own field. The decision makers have also different priorities concerning the decision values and alternatives. Therefore, the collaborative decision-making represents a rich way for decision alternatives' generation and helps the project team in the identification of decision impacts, but these advantages are also the source of potential problems (for instance).

In view to these perceived limits, we propose a project management framework for this early phase of NPPD. This framework is based upon the integration of information and knowledge of collaborative decision-making processes. We developed a conceptual model of collaborative decision-making aiming to identify the critical information for the decision-making as well as product development.

\section{Project Management Framework for the Project Definition Phase}

The referential project management tool developed in Microsoft Project is an important tool in PSA Peugeot Citroën. This is practically the only tool connecting all team members. It is used by the Planning Manager and the Project Manager for the management and activity coordination of the whole project team.

The information available in this tool concerns different project activities organised in different sub projects. Each sub-project concerns the development of one of the vehicle sub-systems, identified in the product breakdown structure.

For every activity, there is the information about the necessary completion time as well as its beginning and its end. As vehicle development projects are big, the number of activities is elevated. In the referential tool there are over $\mathbf{8 0 0}$ macro activities for the time being. We call them "macro" 
because these activities can be decomposed and their completion time is big. For some of these activities, this time is up to 3 months. Thus defined activities are necessary, but this definition intervenes with the project control and coordination.

One of the main issues of the referential project management tool is that activities relationships are not identified in this tool. Therefore the crucial information concerning the critical path is not available. There are several reasons that influenced this condition. First, even with 800 activities, which is a minimum for projects as vehicle development, there is a question of visibility. We already evoked that some of these activities last for 3 months. In this case it is necessary to decompose them and to introduce links between them. Second, the links between activities are time links and some project teams find them very restraining. The process of defining the project objectives is a dynamic and parallel process. Therefore, in order to make a decision and continue to develop the product it is often necessary to make a loop and verify if the information has changed. In this case the project team needs to visualise this dynamic loop which will fix some variables for the product development. They need an option to introduce logic links between activities without necessarily moving or changing dates or activity times.

The objective of our research study is to develop a tool that helps the project manager to have a global overview of the project progression and to identify the crucial points for the project success. This tool also supports the project team's collaborative decision-making process.

Therefore, we propose a tool structure organised on three levels: Decisional level, Informational level and Operational level (see Figure 1). The decisional level considers the collaborative decision-making processes of one project. The informational level is based upon the conceptual collaborative decision-making model and thus, incorporates the intrinsic elements of one collaborative decision. The operational level considers the operational processes of one project. We explain each of these levels further in this manuscript.

The decisional level concerns the collaborative decision-making processes in the NPPD process. These collaborative decision-making processes are represented by a sequence of different collaborative decisions. The relationships between collaborative decisions can be direct or indirect. The relationships are direct when the output of one decision is the input of another and indirect when the output of one decision influences the input of another.

Collaborative decision-making processes contribute to the progressive definition of one project aspect or field, i.e. the project objectives in one project domain are progressively defined in this process. In the decisional level, there are 13 different processes identified. Some of these processes concern optimisation of economic aspects, organisation of production, introduction of important innovations, and development of the vehicle structure. In our research we have not addressed the question of the classification of collaborative decision-making processes. Their definition was elaborated with regard to the PSA Peugeot Citroen culture and know-how. In order to illustrate we will consider for example the purchasing process that is relatively general for all automotive constructers. This collaborative decision-making process concerns the identification of competent suppliers and establishment of adequate relationships with them, i.e. how to work with the suppliers. Some of the decisions that constitute this collaborative decision-making process are: decide what can be produced outside the company, decide who the suppliers capable to develop defined sub-assemblies, decide who are the suppliers that are capable to produce innovated parts? 


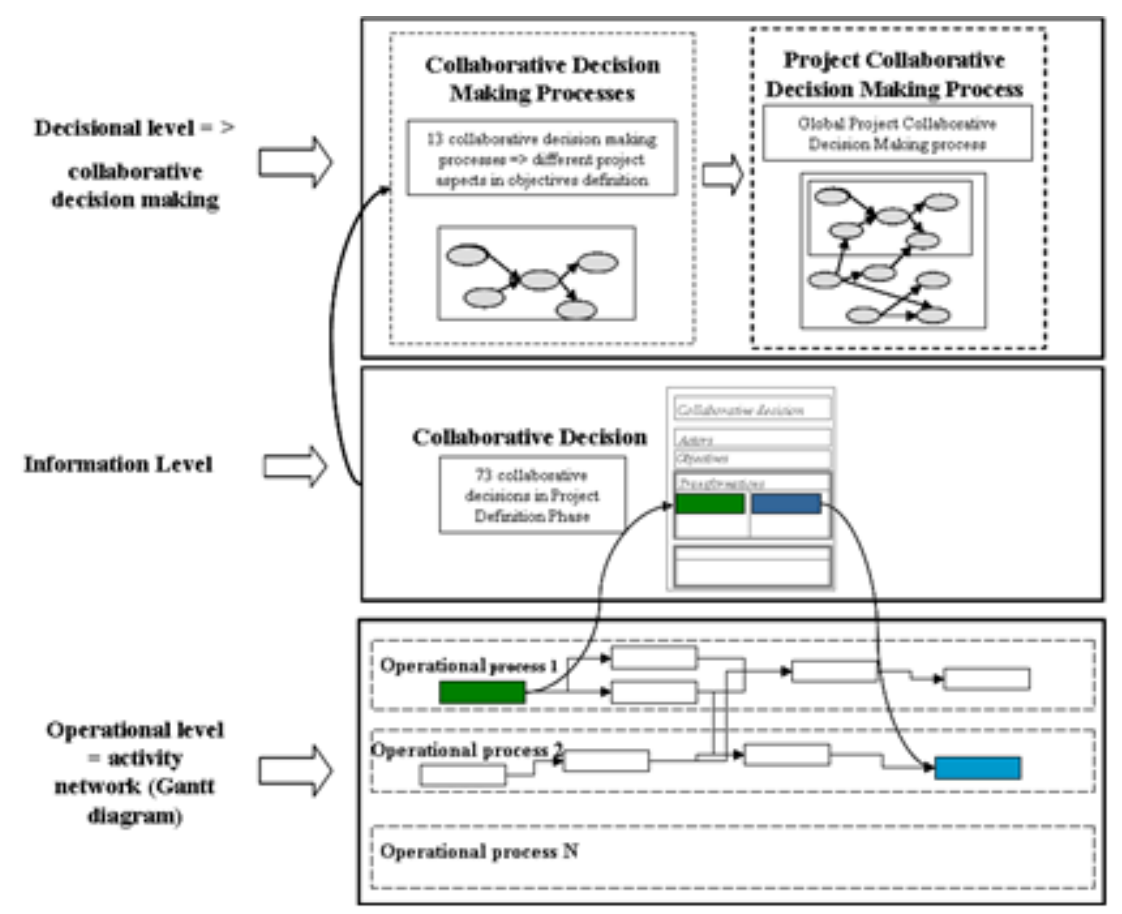

Figure 1 - Project Management Framework (Decisional Level, Informational Level and Operational Level)

Even though we have modelled the collaborative decision-making processes separately (figure 1 Decisional level on the left), the relationships between them are not forgotten. Therefore, for every process we identify the links with other processes. These processes all together constitute the global project collaborative decision-making process (figure 1 - Decisional level on the right), integrating all project development aspects. The advantage of thereby presented processes lies in the fact that it is possible to obtain an overview of just one process or a global overview of the project collaborative decision-making process. This global project overview is very important for the project manager because it contains the information of the crucial points and the project progression path, which help him in the project management.

This project management framework is implemented in MS Project software. Due to the constraints of the software the decisional level is represented in the project management tool in a separate view. This view is nevertheless related to other standard view proposed in the MS project: Gantt, WBS, and budget. In this view, as we implemented this tool in MS Project, the decisions are represented as milestones, because this software does not permit the manipulation of other concepts other than activities or milestones. The relationships used for the collaborative decisionmaking process are the relationships as the disposal in the MS Project.

The Informational level (figure 1) concerns the information of one collaborative decision. This level is developed using the conceptual model that we present in the fourth part of this paper. According to this conceptual model, we have created a document called "the Individual File". The information 
stored in this file is identified and structured with respect to the conceptual model. The objective for this information identification is to point out the crucial elements necessary for the good quality collaborative decision-making. However, the document does not contain all the information we identified as necessary in the collaborative decision-making model. The problem lies in the difficulty in information retrieving or extraction. For example, relationships between project objectives as well as their interdependencies are very difficult and complex to define. In the project development, team members are using the living enterprise knowledge to define them, but for the moment, there is no support containing explicit information. Future developments will consider this lack in order to improve and facilitate decision making for the project team.

The first part of the Individual File concerns different types of actors in the collaborative decisionmaking. There are collaborative decision-making pilots, contributors and decision makers. The presented definition of types of actors in collaborative decision making is important because every actor type defines the role and the responsibilities within the collaborative decision making (Karacapidilis and Papadias 1998b) and can contribute to the decrease of conflicts in decision making process. The pilot is a team member responsible for the definition of project objectives decided in collaborative decision-making. The contributors in the collaborative decision-making are the team members who produce the inputs necessary to make a good decision but do not participate in collaborative decision-making process, because the problem of collaborative decision does not concern or influence directly contributors to the project activity field. The decision makers are the team members that are responsible for the project objective coherence and their own objectives are directly concerned and influenced by the outputs of collaborative decision.

The central part of the Individual File concerns information and corresponding activities of contributing operational processes. These information and activities are essential for quality decision-making on time. If they are not available when the project team has to decide the project objectives, the degree of uncertainty can be endangering project success. That is also, why we have connected this part to risk management. For every input, output or activity to be performed, the concept of criticality is defined and integrated in the Individual file. The criticality is a notion of the risk of obtaining the information on time. It is calculated accordingly to risk management methodology applied in PSA Peugeot Citroën. The quality manager evaluates and includes these risks in the risk database specially designed for risk management.

In this part, we also wanted to exhibit eventual conflicts in the collaborative decision-making. We are based upon the hypothesis that exposing eventual points where conflicts can outbreak will diminish them (Harrington, Soltan et al. 1995). Therefore, we insist on the transparency of individual objectives of every actor. These objectives are highlighted in this part of Individual File along with the activities of each actor. The aim was to give the project manager an overview of possible objective incoherence and out breaking conflicts. The conflicts related to objectives' incoherence is just one of possible conflict types in collaborative decision-making.

The operational level concerns the activity network of the NPPD process. We have not worked directly on the construction and organisation of this level. Nevertheless, the developments of the decisional level and the collaborative decision-making modelling have triggered the internal enterprise reflection related to its organisation. 
The operational level organisation is influenced by the adopted Product Breakdown structure, which is very standard in the project management methodology. But due to the project complexity, the project team has pointed out the necessity to work by "process". Therefore, in this level, 10 operational processes were identified. Their definition is based upon the enterprise know-how.

\section{$4 \quad$ Collaborative Decision Making Process Knowledge and Information Capitalisation}

Decision-making tends to be more and more multi-actor. In his work, Shim (Shim, Warkentin et al. 2002) exposes the transfer from individual decision-making to collective decision-making. Zaraté (Zaraté 2005) adds that all organisational processes are mutating. "Organisational processes evolve and tend to a greater participation of actors in decision-making: responsibilities and initiatives are more and more distributed."

The collaborative decision-making is one type of collective decisions (Zarate and Soubie 2004). The decision-making actors in this decision are experts for one domain of product development.

Therefore, their objectives in the decision-making emanate from this domain. This fact results in the existence of different preferences and judgement values concerning the same problem. The actors are also evaluated upon their realisation of given objectives.

The collaborative decision-making process in the development project is also a very important and efficient way for opinion and information exchange. This aspect of collaborative decision-making represents its real strength. Opinion divergence and differences in problem definition influence the diversity and richness of generated alternatives and therefore the decision quality. This advantage of collaborative decision is at the same time a source of main difficulties in decision-making process. Some of these difficulties are following (Jankovic, Bocquet et al. 2006):

- $\quad$ Different conflicts: for example between objectives of different actors participating in the collaborative decision-making, preferences and strategies each one of them have related to their own objectives (Nutt 1986; Scott 1995; Slabbert 2004; Thunholm 2004);

- Information acquiring problem: in the decision-making process the existence of too much or no information concerning the problem, or relevant information missing (Saunders and Miranda 1998; Kwasitsu 2003; Nutt 2005);

- Influences of value judgment: These value judgements depend upon the role and goals of each actor(Karacapilidis and Papadias 2001).

Here we expose a model of collaborative decision-making. This model was used for the construction of the information level in the project management tool. In our research we use the systemic approach developed by Le Moigne (Le Moigne 1990), permitting the modelling of complex phenomenon. In our work we extend the definition of the process (Figure 2) (Jankovic, Bocquet et al. 2006)

The collaborative decision-making can be perceived as a complex phenomenon for several reasons: 
- In collaborative decision-making participating actors have different objectives, knowledge and vision concerning the problem;

- Objectives of the collaborative decision are different than the objectives of each decision maker and represent an aggregation of these objectives;

- $\quad$ Criteria in collaborative decision-making are not homogenous. Every field touched by collaborative decision has his own criteria and the relationships, as well as influences between these criteria and objectives, are not always known (especially in the case of innovative projects);

- Operational processes influencing and influenced by collaborative decision-making are interconditional and inter-related. Collaborative decision-making is a common decision process for two or more operational processes;

- Collaborative decision-making depends on the information, outputs of different operational processes that are continually changing and thus introduce the unpredictability in the decisionmaking process.

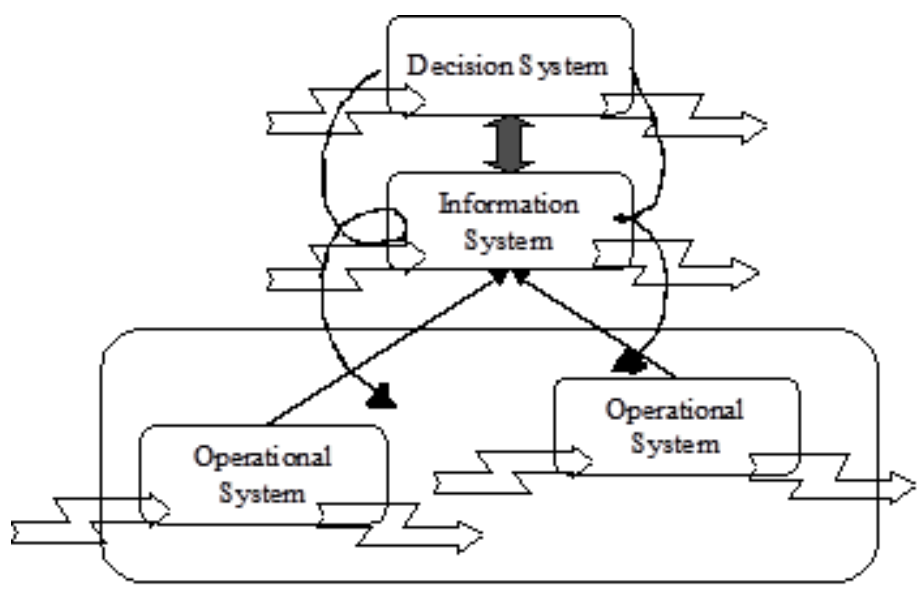

Figure 2- Proposal of Extended System Definition

The following definition of the system given by Le Moigne (Le Moigne 1990) represents a base for complex phenomenon modelling. He gives it in a mnemonic way:

General System is a representation of an active phenomenon comprehended as identifiable by his project in an active environment, in which it functions and transforms teleologically (see Figure 3 ). 


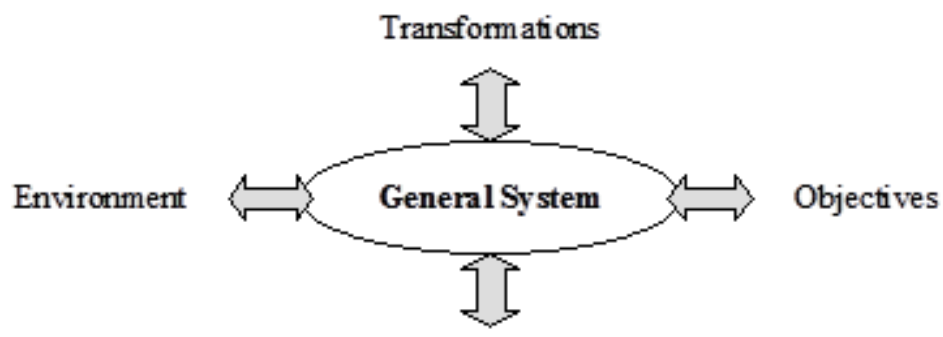

Process

Figure 3 - Definition of the system (Le Moigne 1990)

We used this definition of the system in order to identify the intrinsic elements and information necessary for good and quality decision-making. Therefore, our conceptual model of collaborative decision-making has four views (Jankovic, Bocquet et al. 2006). These views are not to be taken separately into account. There are links between them that are important for the whole model.

The Objectives view concerns different objectives that influence the collaborative decision-making. These objectives represent "what the system is to attain". This view considers different objectives (Stal-Le Cardinal 2000), influence of actor's preferences (Panzarasa, Jennings et al. 2002) and collaborative decision-making objectives.

Environment is a complex surrounding system (Jacqueson 2002), living (actors) and non-living (context), having multiple relationships with the observed object and thus influencing object's behaviour. Three different environments influence collaborative decisions in New Product and Process Development: Decision environment, Project environment and Enterprise environment. We identified these three environments with regard to the influences of different systems in the NPPD process observed on the field. Each of these environments is identified by its context (Hasher and Zack 1984; Brézillon 1999a; Brézillon 1999b; Pomerol and Brezillon 2001; Longueville and Gardoni 2003; Pomerol and Brezillon 2003), determining the influencing factors of collaborative decisionmaking, and different actors relevant for collaborative decision-making with clearly defined roles (Castelfranchi and Falcone 1998; Makaras 2003).

The Process View represents the process of the collaborative decision-making. This view is developed upon the definition of the general decision-making process given by Simon (Simon 1977) and Le Moigne (Le Moigne 1990). Furthermore, it is refined with the information of actual collaborative decision-making on the field. Collaborative decision-making is a complex human-interaction and human-cognition process. There are several specificities of this process:

- In collaborative decision-making there is no optimal solution. The solution has to be negotiated with all collaborators.

- This process is subject, besides the problem of information gathering, to the problem of "getting the good information on time". The NPPD processes are multi-actor processes. Therefore, the decision-making depends on the work of other collaborators or decision makers. 
- The complexity of the collaborative decision-making introduces the problems of coordination and task assignments.

Therefore, we have identified 3 general phases (considering the Canonical Model of Decisionresolution process) (Simon 1977) of the collaborative decision-making process: Identification of the need for decision-making, Decision-making phase and Implementation and Evaluation Phase. This process is based upon the presented decision-making processes and the set of information gathered during our research field.

The Transformations View has the aim to incorporate different states of evolution of one collaborative decision-making system. Transformation (Le Moigne 1990) is a conjunction of an information modification and its result and can be spatial (transfer of information) or form transformation (transformation of the information into new information). These transformations can be divided into two groups: preparatory transformations and implementing transformations.

Preparatory transformations are transformations that are required in order to dispose with elements necessary to decide upon. There are two transformations:

- Transformations from the operational system into the information system,

- Transformation from the information system into the decision system.

- The implementing transformations are transformations related to the implementation of the decided solution:

- Transformation from the decision system into the information system,

- Transformation from the information system into the operational system.

\section{Conclusions}

In this paper we have discussed some of the issues observed in the Project Definition Phase, notably in the field of project management. As this phase is a phase of definition of project objectives, the existing tools have shown some limits: difficulty to plan and organise the phase, the control is not established (control points were identified at the end of the phase), complexity of the developed project management tools and activities' relationships (more than 800 macro-activities).

In order to deal with some of these issues, in this paper, we propose a project management framework implemented in the early stage of new product and process development. The framework consists of three levels: decisional, information and operational level. The implementation of our framework was done in MS Project. The feedback given by some of the users have underlined some advantages:

- $\quad$ The framework by developing and identifying the collaborative decision-making processes helps in the definition of the project trajectory. Moreover it contributes to the global organisation of the project in the early stages of NPPD.

- $\quad$ Through identification of collaborative decision-making elements and information, the framework contributes to the definition of what is to be done, i.e. activities to be executed within this phase. 
- Different levels in the framework constitute complementary and coherent points of view for every actor of the project depending on their roles.

- Within this framework, we have developed in the informational level the roles and responsibilities for every member of the project team. This information enables the control of the global project progress and the development process.

However, in this framework we haven't taken into account the dynamic aspect of the collaborative decision-making process. As we have underpinned already in this paper, the main objective of this research is to support the project team in the collaborative decision-making process and in the project management and control in the early stages. Therefore, the dynamic loops in the collaborative decision-making process are not integrated within this framework. This aspect is very important and some work should be done in the future in this direction.

The identified limits of our research work as well as the feedback and evaluation from the field research have likewise pointed out several perspectives, such as:

- To develop knowledge management tool in order to capitalise the existing information concerning the collaborative decision-making, so that the actor dispose with full information while deciding in this phase,

- To identify and define the correlation between the capitalisation of information and the enterprise performance in order to answer several questions: how the capitalisation influences the enterprise performance? What is the best and most efficient way for the information capitalisation? What is the just necessary information in the early phase of NPPD?

\section{References}

1. Bellut, S. (1990). La compétitivité par la maîtrise des coûts. Conception à coût objectif et analyse de la valeur.

2. Brézillon, P. (1999a). Context in Artificial Intelligence: A survey. Paris, LIP 6, University Paris 6: $1-28$.

3. Brézillon, P. (1999b). Context in Artificial Intelligence: Key elements. Paris, LIP 6, University Paris 6: 1-27.

4. Castelfranchi, C. and R. Falcone (1998). "Towards a theory of delegation for agent-based systems." Robotics and Autonomous Systems 24: 141-157.

5. Harmsen, H., K. G. Grunert, et al. (2000). "Company competencies as a network: The role of product development." Journal of Product Innovation Management 17(3): 194-207.

6. Harrington, J. V., H. Soltan, et al. (1995). "Negotiation in a Knowledge-Based Concurrent Engineering Design Environment." Expert Systems 12(2): 139-147. 
7. Hasher, L. and R. T. Zack (1984). "Automatic processing of fundametal information: the case of frequency of occurence." American Psychologist 39: 1372-1388.

8. Jacqueson, L. (2002). Integration de l'énvironnement en entreprise :

9. Proposition d'un outil de pilotage du processus de création de connaissances environnementales. Paris, L'Ecole Nationale Superieure d'Arts et Métiers.

10. Jankovic, M., J.-C. Bocquet, et al. (2006). Management of the Vehicle Design Process throughout the Collaborative Decision Making Modeling. Integrated Design and Manufacture in Mechanical Engineering - IDMME06, Grenoble, France.

11. Jankovic, M., J.-C. Bocquet, et al. (2006). Integral Collaborative Decision Model in order to Support Project Definition Phase Management. International Design Conference - Design 2006, Dubrovnik, Croatia.

12. Karacapidilis, N. and D. Papadias (1998b). "A Computational Approach for Argumentative Discourse in Multi-Agent Decision Making Environments." Al Communications Journal 11(1): 21-33.

13. Karacapilidis, N. and D. Papadias (2001). "Computer supported argumentation and collaborative decision making: the HERMES system." Information Systems 26(4): 259-277.

14. Kwasitsu, L. (2003). "Information-seeking behavior of design, process, and manufacturing engineers." Library \& Information Science Research 25(4): 459-476.

15. Le Moigne, J.-L. (1990). La modélisation des systèmes Complexes. Paris, Dunod.

16. Longueville, B. and M. Gardoni (2003). A Survey of Context Modelling: Approaches, Theories and Use for Engineering Design Researches. ICED 03: 14th International Conference on Engineering Design, Stockholm, Sweden.

17. Makaras, G. (2003). Decision Support Systems in the 21st Century, Prentice Hall.

18. Nutt, P. C. (1986). "Decision style and its impact on managers and management." Technological Forecasting and Social Change 29(4): 341-366.

19. Nutt, P. C. (2005). "Search during decision making." European Journal of Operational Research 160(3): 851-876.

20. Panzarasa, P., N. R. Jennings, et al. (2002). "Formalizing collaborative decision-making and practical reasoning in multi-agent systems." Journal of Logic and Computation 12(1): 55-117.

21. Pomerol, J. C. and P. Brezillon (2001). About some relationships between knowledge and context. Modeling and Using Context, Proceedings. 2116: 461-464.

22. Pomerol, J. C. and P. Brezillon (2003). Context proceduralization in decision making. Modeling and Using Context, Proceedings. 2680: 491-498.

23. Saunders, C. and S. Miranda (1998). "Information acquisition in group decision making." Information \& Management 34(2): 55-74. 
24. Scott, S. G., Bruce, R. A. (1995). "Decision-making style: the development and assessement of the new measure." Educational and Psychological Measurement 55(5): 818-831.

25. Shim, J. P., M. Warkentin, et al. (2002). "Past, present, and future of decision support technology." Decision Support Systems 33(2): 111-126.

26. Simon, H. A. (1977). The New Science of Management Decisions. Englewood-Cliffs, Prentice hall.

27. Slabbert, A. D. (2004). "Conflict management styles in traditional organisations." The Social Science Journal 41(1): 83-92.

28. Stal-Le Cardinal, J. (2000). Etude des dysfonctionnements dans la prise de décision. Application au choix d'acteur. Industrial Engineering Laboratory. Paris, ECP.

29. Thunholm, P. (2004). "Decision-making style: habit, style or both?" Personality and Individual Differences 36(4): 931-944.

30. Whelton, M., G. Ballard, et al. (2002). "A Knowledge Management Framework for Project Definition." Electronic Journal of Information Technology in Construction -ITcon 7: 197-212.

31. Zaraté, P. (2005). Des Systèmes Interactifs d'Aide à la Décision aux Systèmes Coopératifs d'Aide à la Décision. Toulouse, Institut National Polytechnique de Toulouse.

32. Zaraté, P. and J.-L. Soubie (2004). "An Overview of Supports for Collective Decision Making." Journal of Decision Systems 13(2): 211-221. 